\title{
Emergent Narrative and Late Commitment
}

\author{
Ivo Swartjes, Edze Kruizinga, Mariët Theune, and Dirk Heylen \\ Human Media Interaction group, Twente University \\ [swartjes | kruizingaee | theune | heylen] @cs. utwente.nl
}

\begin{abstract}
Emergent narrative is an approach to interactive storytelling in which stories result from local interactions of autonomous characters. We describe a technique for emergent narrative that enables the characters to fill in the story world during the simulation when this is useful for the developing story.
\end{abstract}

\section{Introduction}

The Virtual Storyteller [1] is a framework that can be used to author a story world, simulate virtual characters that live their lives in this story world, and tell stories about the resulting event sequence. The approach is that of emergent narrative [2], meaning that stories are not scripted in advance, but result from local interactions of virtual character agents. To facilitate the emergence of interesting stories, we give these character agents some responsibility for story progression, informed by techniques used by actors in improvisational theater [3]. One of these techniques is to fill in the story world in line with what the emerging story needs. Objects are added, character quirks and relationships defined, and the back stories of the characters are conveniently filled in, when this is useful for story progression. In this paper, we describe our exploration of this idea, and illustrate how we use it in the Virtual Storyteller.

\section{Late Commitment}

Emergence, as a guiding principle in both improvisational theater and emergent narrative, implies that there is no clear relationship for the author between the initial setup of the story world and what emerges. We would like her to be able to author parts of the story world in terms of potentiality, so that elements can be introduced whenever they become useful in the simulation.

For the Virtual Storyteller, we have enabled this by introducing a type of operators to the story domain that we call framing operators. The effects of a framing operator describe commitments to information about the story world, rather than changes (as with actions and events). Where a normal action is pursued in character (i.e., the agent's character does the action), a framing operator is an action out of character (i.e., the agent itself does the action, as if it says to the rest of the agents: "let's pretend my character hated your character, OK?"). The execution of a framing operator should create the illusion that its effects have been true since the start of the simulation. The idea builds on initial state revision in story planning [4]. 


\section{Usage Examples}

We have fully implemented support for framing operators in the Virtual Storyteller and have run experiments within the domain of pirate stories. To illustrate how late commitment facilitates the emergent narrative process, we sketch two examples of how we use it:

Finding motivations for the adoption of goals. In the Virtual Storyteller, character agents can adopt goals when the preconditions of these goals are met. For instance, adopting a goal of plundering another ship might require that there is another ship in sight, and that the character adopting the goal is a pirate captain. If these circumstances do not apply, the preconditions can still be achieved by introducing a ship in sight, and endowing one of the characters with the role of pirate captain.

Filling in the environment to support action selection. If the captain of the ship has adopted a goal to find out whether an approaching ship is friend or foe, he can make a plan involving looking through a binocular. This binocular can be framed to be in the captain's cabin, and the captain will plan to go to his cabin to get it.

We have found that the technique of late commitment increases the flexibility of character agents to improvise, not only by using framing operators to aid in the planning process, but also by being able to create the necessary context for the adoption of desired character goals. We plan to investigate how this technique can also be used for the agents to actively find reasons for emotional reactions and belief changes.

\section{Acknowledgements}

This research has been supported by the GATE project, funded by the Netherlands Organization for Scientific Research (NWO) and the Netherlands ICT Research and Innovation Authority (ICT Regie).

\section{References}

1. Theune, M., Rensen, S., op den Akker, R., Heylen, D., Nijholt, A.: Emotional characters for automatic plot creation. In: Technologies for Interactive Digital Storytelling and Entertainment (TIDSE). (2004)

2. Aylett, R.: Emergent Narrative, Social Immersion and "Storification". In: Proceedings of the 1st International Workshop on Narrative Interaction for Learning Environments, Edinburgh (2000)

3. Swartjes, I., Vromen, J.: Emergent story generation: Lessons from improvisational theater. In: Intelligent Narrative Technologies: Papers from the AAAI Fall Symposium. Number FS-07-05 in AAAI Fall Symposium Series (2007)

4. Riedl, M., Young, M.: Story planning as exploratory creativity: Techniques for expanding the narrative search space. In: Proceedings of the 2005 IJCAI Workshop on Computational Creativity. (2005) 